\title{
Protein Overexpression and Gene Amplification of c-erb B-2 in Pulmonary Carcinomas: A Comparative Immunohistochemical and Fluorescence In Situ Hybridization Study
}

Naoko Hirashima, M.D., Wataru Takahashi, M.D., Shinpei Yoshii, M.D., Tetsu Yamane, M.D., Akishi Ooi, M.D.

Departments of Pathology (NH, TY, AO) and Surgery (WT, SY), Yamanashi Medical University, Yamanashi, Japan

Amplification of the c-er $b \mathrm{~B}-2$ gene (located on 17q11.2-12) is accompanied by overexpression of its cell surface receptor product, $\mathrm{p} 185^{\mathrm{ERBB} 2}$. In pulmonary carcinomas, however, there has been disagreement between the reported frequencies of gene amplification and overexpression. To clarify their relationship, the correlation between the cellular expression of $\mathrm{p}^{185^{\mathrm{ERBB} 2}}$ and the level of c-erb B-2 gene amplification was studied. A total of 195 pulmonary carcinomas (182 primary and 13 metastatic) were examined immunohistochemically using a polyclonal antibody, which recognizes the internal domain of the human c-erb B-2 protein, and positive tumors were further examined for the gene amplification by dual-color fluorescence in situ hybridization using probes for centromere 17 and 17q11.2-12. By immunohistochemistry, distinct membrane staining was found in an adenocarcinoma, a large cell carcinoma and a metastatic carcinoma from the breast, and cytoplasmic and/or faint membranous staining was observed in 23 nonsmall cell lung carcinomas. It was in the two primaries and the metastatic carcinoma that more than 8-fold amplification of c-erb B-2 was found by fluorescence in situ hybridization. Especially, in the two primary carcinomas, tumor cells had amplified genes with the signals forming one or two clusters, indicating that the amplified gene was present in homogeneously staining regions. Among the 23 tumors, three tumors showed low-level amplification (less than 3-fold), which was differentiated from polysomy 17 found in the other two. In the 30 non-

Copyright () 2001 by The United States and Canadian Academy of Pathology, Inc.

VOL. 14, NO. 6, P. 556, 2001 Printed in the U.S.A.

Date of acceptance: November 15, 2000.

Address reprint requests to: Akishi Ooi, M.D., Department of Pathology, Yamanashi Medical University, 1110 Shimokato, Tamaho-cho, Nakakoma-gun, Yamanashi 409-3898, Japan; e-mail: aooi@res. yamanashi-med.ac.jp; fax: 81-55-273-6727. small cell lung carcinomas selected at random from 151 with negative immunostaining, there were five trisomy 17 , but no tumors with the gene amplification. This suggests that although c-erb B-2 amplification in pulmonary carcinoma is rare, it occurs in the form of a homogeneously staining region and is thought to control the overexpression of the protein in the cell membrane. New adjuvant therapy using a humanized antibody to the oncoprotein may be beneficial to patients with these tumors.

KEY WORDS: c-erbB-2, Fluorescence in situ hybridization, Pulmonary carcinoma.

Mod Pathol 2001;14(6):556-562

The human proto-oncogene c-erb B-2 (also called HER-2 and neu encodes a 185kd transmembrane phosphoprotein (p185 ${ }^{\text {ERBB2}}$ ) related to the epidermal growth factor receptor, which has tyrosine kinase activity. Although p $185^{\mathrm{ERBB} 2}$ is a receptor for a still poorly characterized growth ligand, it is assumed to be involved in the regulation of cell growth and differentiation (1). Increased p185 ${ }^{\text {ERBB2 }}$ expression is associated with malignant cell transformation (2). Interest in the clinical application of c-erbB-2 was initially stimulated by the work of Slamon et al. (3), who showed that amplification of this gene in breast cancer correlated significantly with both time to relapse and overall survival. In their subsequent study, they found almost complete concordance between the gene amplification detected by Southern blot analyses and the overexpression as determined by Northern blot, Western blot and/or immunohistochemical analyses (4). Since then, most, but not all, investigators have found that either amplification or increased expression of the c-erbB-2 gene correlates with poor prognosis in many different human primary tumors including ovarian (5), pulmonary (6) and endometrial carcinomas (7). In non-small cell lung carcinomas 
(NSCLCs), some investigators reported that more than half of the tumors overexpressed the oncoprotein (8); however, according to others, its frequency was less than $2 \%$ (9). Previous Southern blot studies raised the frequency of zero to several percent (10-13). The discordance between the frequencies of c-erbB-2 overexpression, and overexpression and gene amplification in NSCLCs may be attributed to quantitatively and/or qualitatively different mechanisms of gene amplification from those in other carcinomas.

Fluorescence in situ hybridization (FISH) is a potent tool to investigate not only numeral aberration, but also the amplification status of genes in interphase nuclei. Applying this technique to formalinfixed, paraffin-embedded tissues, we clarified that in gastric adenocarcinomas, high-level amplification of c-erbB-2 principally in homogeneously staining regions (HSRs) control overexpression of the protein in the cytoplasmic membrane $(14,15)$. In the present study, we compared the findings of immunohistochemistry and FISH to clarify c-erbB-2 aberrations in primary lung cancers. To the best of our knowledge, this is the first study that examined the c-erbB-2 status in the primary lung cancers by FISH. Recently, new adjuvant chemotherapy using an anti-c-erbB-2 antibody was being tested in clinical trials (16). Therefore, it is crucial to identify patients whose tumors respond to the agent. The use of FISH and interphase cytogenetics may be useful in the management of such patients.

\section{MATERIALS AND METHODS}

\section{Tissue Samples}

We examined 195 pulmonary carcinomas consecutively resected at the Department of Surgery, Yamanashi Medical University between 1983 and 1999. There were 182 primary lung cancers (147 adenocarcinomas, 24 squamous cell carcinomas, 5 large cell carcinomas, 6 small cell carcinomas) and 13 metastatic cancers from the colon (9), breast (3) and stomach (1).

\section{Histology and Immunohistochemistry}

Serial sections $(4 \mu \mathrm{m})$ that had been cut from representative formalin-fixed, paraffin-embedded cancer tissue and placed onto silanated glass slides (Matsunami, Tokyo, Japan) were used for hematoxylin-eosin staining, immunohistochemical detection of the c-erbB-2 protein and FISH analysis. The immunohistochemical study was carried out with a polyclonal antibody (Nichirei, Tokyo, Japan; working dilution, 1:100), which recognizes the internal domain of the human c-erbB-2 protein. Antibody binding was visualized by the avidin-biotin- peroxidase complex procedure. The specificity of the antibody and validity of the methodology were verified by our previous studies on gastric cancers $(14,15)$.

All slides were reviewed by three pathologists $(\mathrm{NH}$, TY, AO), who were unaware of the gene amplification. Each slide was scored according to the following scale: -, no discernible staining or, at most, faint, background-type staining; $1+$, faint staining with a discernible but incomplete plasma membrane pattern and/or unequivocal cytoplasmic staining; $2+$, unequivocal membrane staining with moderate intensity; $3+$, strong and complete plasma membrane staining. This score is basically similar to those used for breast cancers $(17,18)$ except $1+$. Many studies have chosen to ignore the cytoplasmic staining (18, 19); however, we tentatively included this in $1+$, because it was virtually impossible to differentiate faint membranous staining from cytoplasmic staining in several cases and to compare previous findings using similar standards.

\section{$\mathrm{FISH}$}

FISH analysis was applied to all immunostainingpositive tumors and the negative tumors selected at random. Numerical changes affecting chromosome 17 and the c-erbB-2 gene locus were determined using the fluorescently labeled DNA probes purchased from Vysis, Inc (Downers Grove, IL). The HER-2/ neuSpectrumOrange probe contains DNA sequences specific for the HER-2/neu human gene locus and hybridizes to region 17q11.2-q12 of human chromosome 17. The CEP 17 (chromosome enumeration probe 17)/SpectrumGreen probe contains alphasatellite DNA that hybridizes to the D17Z1 locus (centromere region of chromosome 17). The probes were provided predenatured and premixed in hybridization buffer. The CEP 17 probe was used as the control to determine the copy number for chromosome 17 . Removal of protein from the tissue sections was conducted as previously described $(14,15)$. In brief, deparaffinized and rehydrated tissue sections mounted on silanated slides were incubated in $20 \%$ sodium bisulfite $/ 2 \times$ standard saline citrate at $43^{\circ} \mathrm{C}$ for 20 minutes. After washing in $2 \times$ SSC, the slides were treated with proteinase $\mathrm{K}(25 \mathrm{ng} / \mathrm{mL})$ (BoehringerMannheim, Mannheim, Germany) at $37^{\circ} \mathrm{C}$ for 30 minutes. Denaturation, hybridization, and posthybridization were carried out according to the manufacturer's protocol. The tissue sections were counterstained with 4', 6-diamidine-2'-phenylindole dihydrochloride (DAPI) in an antifade solution (Oncor, Gaithersburg, MD) and examined with an epifluorescence microscope (Olympus, Tokyo, Japan) equipped with Triple Bandpass Filter sets (Vysis) for DAPI, SpectrumOrange and SpectrumGreen. Copy numbers for centromere 17 and c-erbB-2 signals were counted, respec- 
tively, in at least 20 cancer nuclei and 200 noncancerous cells, according to the method of Persons et al. (20). For each tumor the ratio of the c-erbB-2 signals to centromere 17 signals were calculated. Cells were scored only when at least one bright centromeric and one c-erbB-2 signals in a distinct nuclear border were present. When c-erbB-2 signals coalesced to clusters, FISH images were taken with a CCD camera (Photometrics, Tucson, AZ) and the copy number was calculated by comparing signal intensities of clusters and single copies using IPLab Scientific imaging software (Scanalytics Inc, Fairfax, VA). Furthermore, according to the centromere 17 number of the predominant population, tumors were arbitrarily classified as different ploidy of chromosome 17: tumors were classified as disomic, trisomic, or tetrasomic if more than $50 \%$ of nuclei contained two, three, or four copies of centromeric signals, respectively. When the proportion of cells with negative nuclei exceeded $20 \%$, the procedure was regarded as suboptimal and repeated once or abandoned. The FISH images were taken using photographic camera and recorded on film slides.

\section{RESULTS}

\section{Immunohistochemistry}

Positive immunostaining of c-erbB-2 protein was found in 26 (13.3\%) of the 195 pulmonary carcinomas analyzed. One well-differentiated adenocarcinoma (Case 1) (Fig. 1A) and a metastatic carcinoma from the breast (Case 26) (Fig. 1B) showed a 3+ staining pattern, and a large cell carcinoma showed a $2+$ staining as shown in Figure 2. In these three tumors, most cancer cells were c-erbB-2 positive and there was no intratumoral heterogeneity in the gene expression. In the other 23 primary pulmonary cancers the reaction products was found faint as shown in Figure 3, and were judged as the 1+ pattern. In these tumors, uneven distribution of the positive cells in the tumor was often found. In the remaining 169 tumors, including all 6 SCLCs, no immunostaining was found. The histopathologic findings of the 26 positive cases are summarized in Table 1.

\section{FISH}

FISH analysis was applied to 26 immunostainingpositive tumors and 30 negative NSCLCs selected at random. Successful probe hybridization was achieved in 48 (85.7\%) (two $3+$ tumors, one $2+$ tumor, nineteen $1+$ tumors, and 26 non-staining tumors). The test failed in the remaining eight cases because the intensity of the hybridization signals of c-erbB-2 was too faint to count. The findings of the
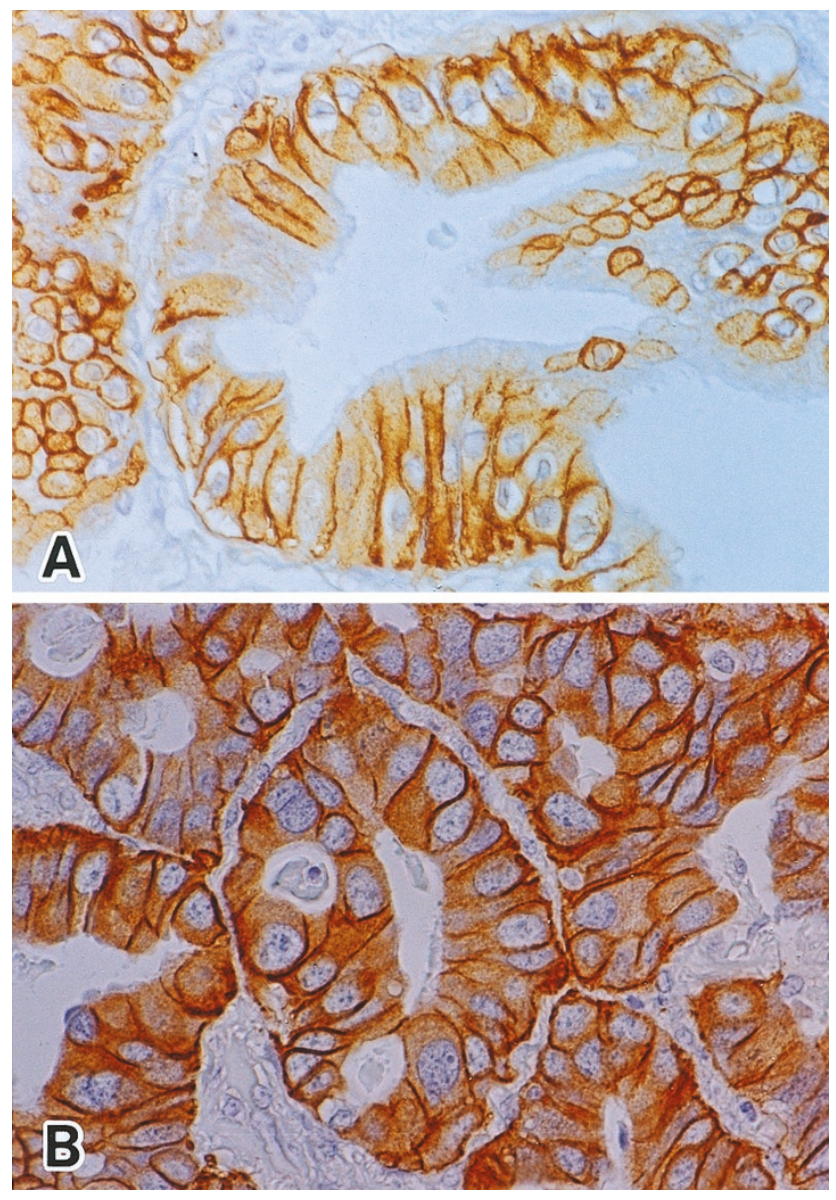

FIGURE 1. $3+$ staining tumors. Strong reaction products were clearly localized on the lateral and basal sides of tumor cells. A, well differentiated adenocarcinoma (Case 1). B, metastatic carcinoma from the breast (Case 26) $(\times 300)$.

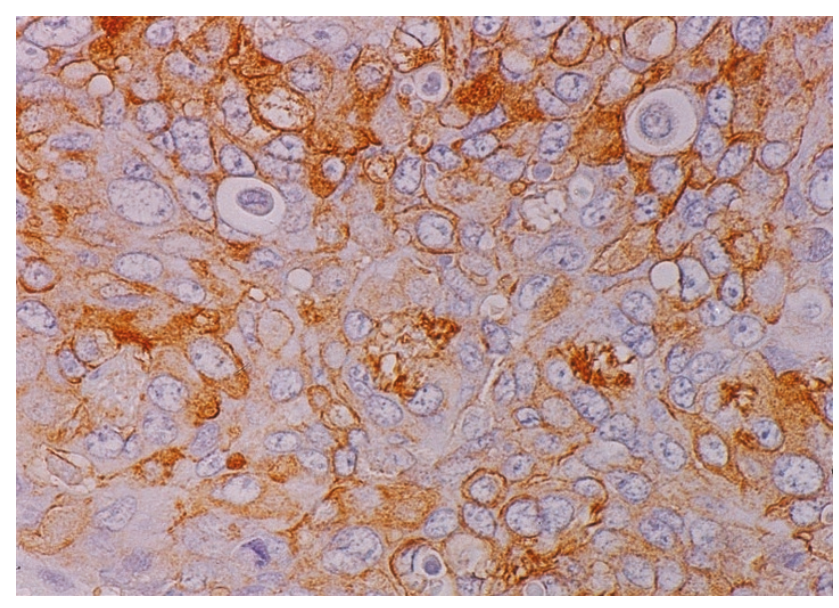

FIGURE 2. $2+$ staining tumor. Unequivocal membranous pattern, moderate intensity. Large cell carcinoma of the lung (Case 25) $(\times 300)$.

signal enumeration of the 26 tumors with positive immunostaining are shown in Table 1.

In the adenocarcinoma (Case 1) and the large cell carcinoma (Case 25), immunostained $3+$ and $2+$, respectively, cancer cells typically had one or occasionally two clusters of the c-erbB-2 signals as 


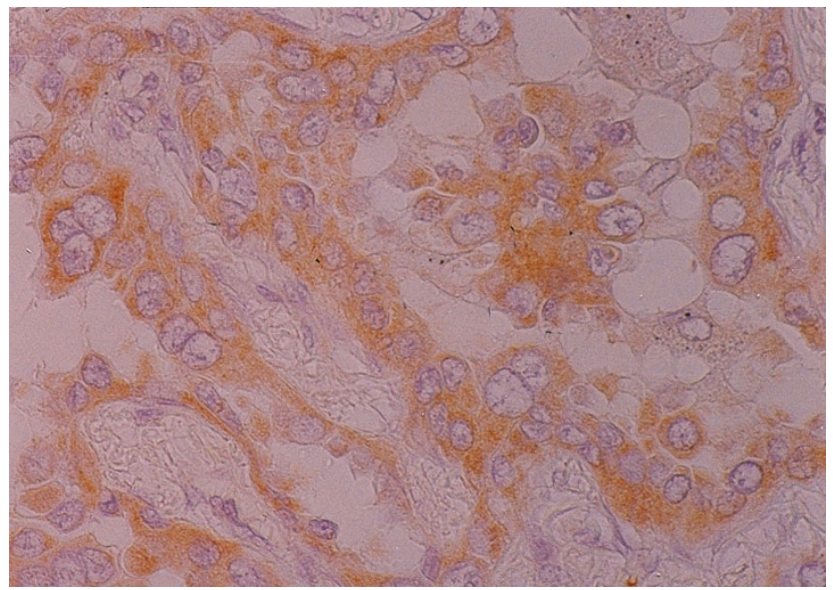

FIGURE 3. $1+$ staining tumor showing cytoplasmic staining (Case 14) $(\times 300)$.

shown in Figure 4. The precise enumeration was impossible in most cancer cells due to the tight coalesced signals, but image analysis of each cluster showed approximately 20-fold stronger fluorescence as single copy signals. In the metastatic cancer from the breast (Case 26), immunostained 3+, cancer cells had less tightly coalesced clusters and scattered signals as shown in Figure 5, and the c-erbB-2 copy number per nucleus was $24.2 \pm 13.4$ (mean $\pm \mathrm{SD}$ ). (In this case similar amplification and $3+$ immunostaining were found in the primary tumor of the breast.) Among the nineteen 1+ tumors, three cases (Cases 12, 14, and 21) had several (maximum 5) signals in addition to the centromeric signals as shown in Figure 6. Normal bronchial epithelial cells and non-neoplastic stromal or inflammatory cells associated with the tumors had one or two centromere 17 and c-erbB-2 signals. The ratio of c-erbB-2 signals to centromere 17 signals of the non-neoplastic cells was $1.10 \pm 0.42$ (mean \pm SD). Using the Kruskal-Wallis test, six tumors (Cases $1,12,14,21,25$, and 26) had significantly higher $(P<0.01)$ ratios than this figure and were considered amplification positive. Three tumors (Cases 1, 25 , and 26) with mean amplification ratios more than 8-fold were classified as high-level amplification tumors and those (Cases 12, 14, and 21) with ratios less than three were regarded as low-level amplification tumors.

\section{DISCUSSION}

In the present study, we found various levels of immunoreactivity of c-erbB-2 in 25 (14.2\%) of 176 NSCLCs, and no positive tumors in 6 SCLCs. Although there is general agreement that there are no c-erbB-2 positive SCLCs, the frequency of c-erbB-2 positivity among NSCLCs is still controversial. This is mainly because variable criteria have been used to interpret the results of immunohistochemistry. Kern et al. found $33.3 \%$ of NSCLCs (10 of 29 ade-

TABLE 1. Histological Classification and Results of Immunohistochemistry and FISH Analysis

\begin{tabular}{|c|c|c|c|c|c|}
\hline \multirow{2}{*}{$\begin{array}{l}\text { Case } \\
\text { Number }\end{array}$} & \multicolumn{2}{|c|}{ Immunohistochemistry } & \multicolumn{3}{|c|}{ FISH Analysis } \\
\hline & $\begin{array}{l}\text { Histological } \\
\text { Classification }\end{array}$ & $\begin{array}{l}\text { Type of } \\
\text { Staining }\end{array}$ & $\begin{array}{l}\text { Ratio of c-erbB-2 to } \\
\text { Chromosome } 17 \text { (means } \pm \text { SD) }\end{array}$ & $\begin{array}{c}\text { Status of } \\
\text { Amplification }\end{array}$ & $\begin{array}{l}\text { Chromosome } 17 \\
\text { Ploidy }\end{array}$ \\
\hline 1 & Adenoca. well & $3+$ & $9.45 \pm 4.40$ & High level (CS) $)^{\#}$ & Disomy \\
\hline 2 & Well & $1+$ & $1.01 \pm 0.35$ & - & Disomy \\
\hline 3 & Well & $1+$ & $1.05 \pm 0.32$ & - & Disomy \\
\hline 4 & Well & $1+$ & $1.15 \pm 0.53$ & - & Disomy \\
\hline 5 & Well & $1+$ & $1.27 \pm 0.37$ & - & Disomy \\
\hline 6 & Well & $1+$ & $1.15 \pm 0.50$ & - & Disomy \\
\hline 7 & Well & $1+$ & $0.98 \pm 0.41$ & - & Disomy \\
\hline 8 & Well & $1+$ & $1.15 \pm 0.43$ & - & Disomy \\
\hline 9 & Well & $1+$ & $1.18 \pm 0.49$ & - & Disomy \\
\hline 10 & Well & $1+$ & NSD & & \\
\hline 11 & Well & $1+$ & $1.04 \pm 0.34$ & - & Trisomy \\
\hline 12 & Well & $1+$ & $2.52 \pm 0.86$ & Low level & Disomy \\
\hline 13 & Well & $1+$ & $1.19 \pm 0.40$ & - & Disomy \\
\hline 14 & Well & $1+$ & $2.81 \pm 1.49$ & Low level & Disomy \\
\hline 15 & Well & $1+$ & $1.21 \pm 0.32$ & - & Trisomy \\
\hline 16 & Well & $1+$ & $1.28 \pm 0.51$ & - & Disomy \\
\hline 17 & Mod & $1+$ & NSD & & \\
\hline 18 & Mod & $1+$ & $1.17 \pm 0.37$ & - & Disomy \\
\hline 19 & Mod & $1+$ & $1.30 \pm 0.59$ & - & Disomy \\
\hline 20 & Mod & $1+$ & $1.18 \pm 0.41$ & - & Disomy \\
\hline 21 & Mod & $1+$ & $1.98 \pm 0.90$ & Low level & Trisomy \\
\hline 22 & Por & $1+$ & NSD & & \\
\hline 23 & Squamous. mod & $1+$ & $1.13 \pm 0.43$ & - & Disomy \\
\hline 24 & Mod & $1+$ & NSD & & \\
\hline 25 & Large cell ca. & $2+$ & $8.66 \pm 2.90$ & High level (CS) $)^{\#}$ & Disomy \\
\hline 26 & Metastatic ca. (breast) & $3+$ & $9.39 \pm 4.56$ & High level (MSS) & Disomy \\
\hline
\end{tabular}

Well, well differentiated; mod, moderately differentiated; por, poorly differentiated; NSD, no signal detected; NA, no amplification; CS, clustered signal; MSS, multiple scattered signals.

\# Copy number of c-erbB-2 was calculated by image analyzer. 

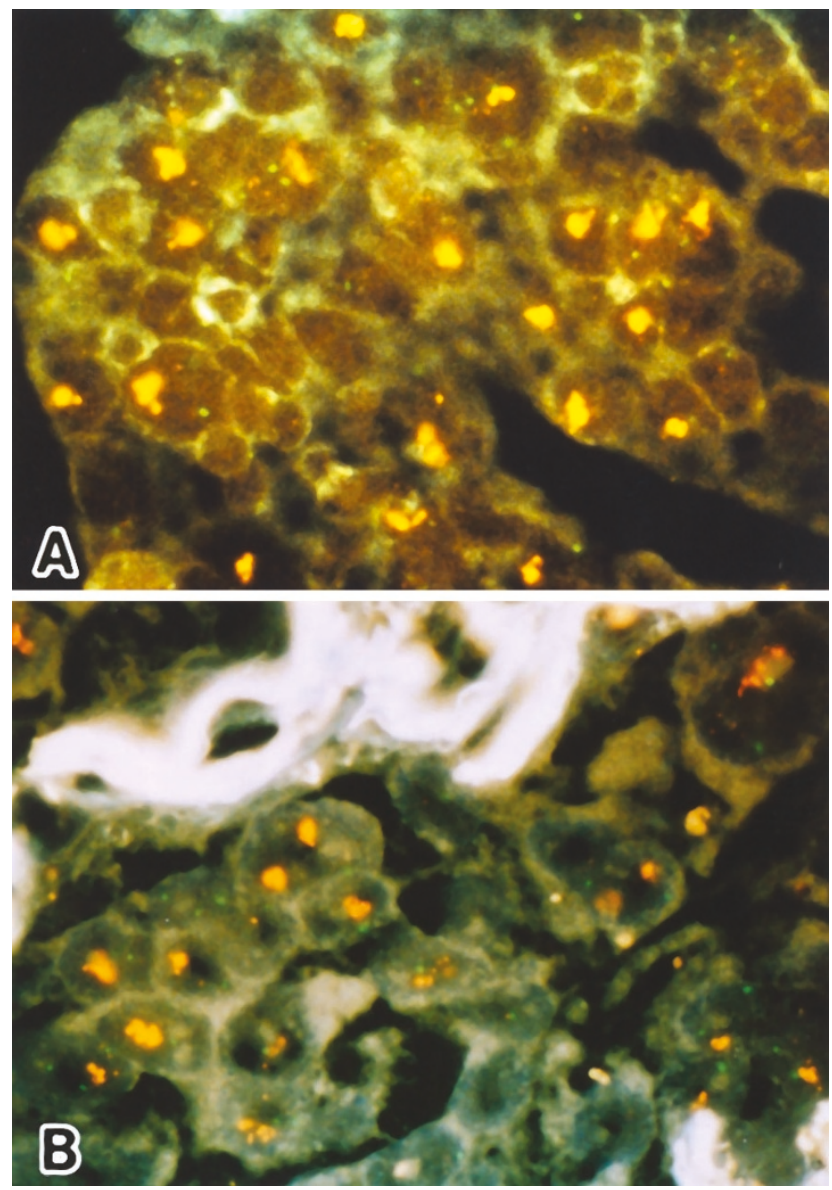

FIGURE 4. Fluorescence in situ hybridization of primary pulmonary carcinomas with $3+$ immunostaining (A, Case 1) and 2+ immunostaining (B, Case 25). Amplified c-erbB-2 genes forming clusters in the cancer nuclei $(\times 750)$

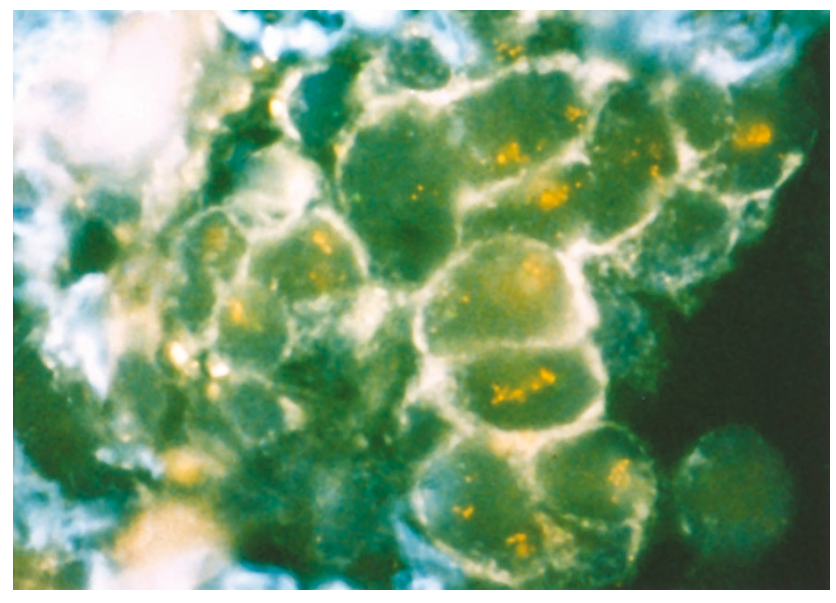

FIGURE 5. Fluorescence in situ hybridization of the metastatic cancer from the breast with $3+$ immunostaining (Case 26). Cancer nuclei have amplified c-erbB-2 signals loosely coalesced $(\times 750)$.

nocarcinomas and 5 of 16 squamous cell carcinomas) overexpressed $\mathrm{p} 185^{\mathrm{ERBB} 2}$ relative to the levels of expression seen in the uninvolved bronchial epithelium (6). Shi et al. reported that $58.8 \%$ of NSCLCs (33 of 41 adenocarcinomas and 24 of 55

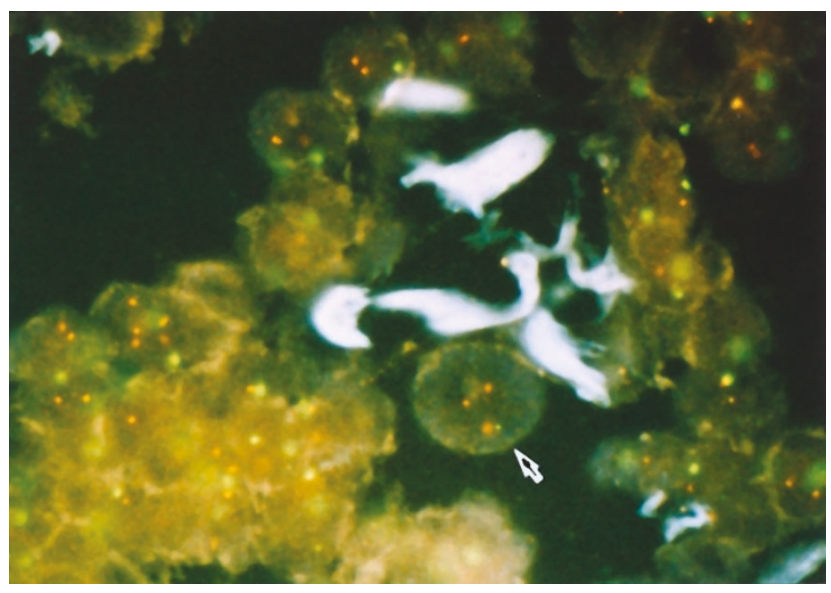

FIGURE 6. Fluorescence in situ hybridization of the primary carcinoma with $1+$ staining (Case 14). Cancer nucleus with two additional copies of c-erbB-2 to centromere 17 (arrow). In this nucleus the other two c-erbB-2 signals were out of focus $(\times 750)$.

squamous cell carcinomas) expressed p185 ${ }^{\mathrm{ERBB} 2}$ (8) when both membranous and cytoplasmic stainings were considered as positive. Recently, most investigators have reached consensus on interpretation of the immunohistochemical stains of breast cancers: only membranous patterns are considered positive $(18,19)$. According to this criterion, McCann et al. reported that only one $(1.2 \%)$ of 84 NSCLCs had intense positive reactions for this oncoprotein (9).

Furthermore, in most studies on breast cancer using a four-tier grading system to evaluate immunohistochemistry, which appeared similar to that of the present study except for $1+$, only $2+$ and $3+$ stainings are considered as meaningful because they are accompany unequivocal gene amplification $(17,18)$. In the present study, definite membranous staining was found in only two $(1.2 \%)$ of 176 NSCLCs and its frequency corresponded to that reported by McCann et al. (9). Furthermore, it was in the two primary, and one metastatic cancer with $3+$ staining that a definite high-level c-erbB-2 amplification was found by FISH. The two primary cancers showed cancer nuclei with one or two clustered signals, which corresponded to the FISH image of interphase nuclei with amplified genes in HSR $(14,15)$. The FISH image of loose clusters with scattered signals found in the metastatic cancer from the breast may represent complex translocations of the amplified genes in HSR to other chromosomes, which have been demonstrated in several breast cancer cell lines (21). This is consistent with the present assumption based on our previous FISH studies on gastric cancer that high-level amplification principally produces the c-erbB-2 gene HSR form and controls overexpression of the protein in the cytoplasmic membrane $(14,15)$.

Before introduction of the FISH technique, c-erbB-2 amplification was detected using Southern 
blot hybridization. Several Southern blot hybridization studies have examined the c-erbB-2 amplification in NSCLCs, unfortunately none were comparative studies with protein overexpression (10-13). Shiraishi et al. (10) found c-erbB-2 amplification in only one of 51 primary NSCLCs (one in 21 adenocarcinomas), Cline and Battifora (11), 1 in 27 (1 in 16 adenocarcinomas) and Schneider et al. (12), 2 in 60 (one adenocarcinoma and one squamous cell carcinoma). Slebos et al. (13), however, reported no tumors in 21 adenocarcinomas examined. The levels of the amplification also varied: 4 -fold in one case, 6 -fold in one case, and 20-fold in two cases. The levels of amplification detected by Southern blotting were not infrequently lower than those seen by FISH because in solid tumors such as lung cancer the extracted tumor DNA is always diluted by DNA of noncancerous tissue. Another pitfall in detecting gene amplification by Southern blotting is that the quantitation of amplification relates to the reference marker. Thus, it is occasionally difficult to distinguish lowlevel gene amplification from an excess of gene copies secondary to aneusomy by conventional Southern blot analysis (14). It is also difficult to differentiate the two categories by FISH analysis using tissue sections, because when cutting 4 microns into a 10 to $15 \mathrm{mi}-$ cron nucleus, unavoidable signal heterogeneity is caused by nuclear truncation. Thus, analysis of adequate numbers of nuclei within a specimen to correct for this potential problem should be done (22). Recently, the feasibility of enumerating two-color FISH signals in 20 nuclei on tissue sections was demonstrated by statistical analysis (20). Therefore we believe that in this study, such artifacts were considerably reduced, and that the numerical changes found in three tumors (Cases 12, 14, and 21) were low-level amplifications, rather than increases due to polysomy. Although the molecular genetic mechanisms of such low-level amplification are unknown at present, these low-level amplifications do not translate into definite protein overexpression.

In addition to investigating carcinogenesis and giving prognosis for cancer patients, clarification of expression and amplification of c-erbB-2 is having a new impact on cancer treatment. Recently, a recombinant humanized antibody against the extracellular domain of c-erbB-2 (Trastuzumab) was approved for the treatment of solid tumors. Also, the United States Food and Drug Administration approval was granted on the basis of findings on the use of the agent in the treatment of a subset of patients with metastatic breast cancer overexpressing the c-erbB-2 (23). Although they are very rare, pulmonary carcinomas with high overexpression levels in the cellular membrane due to gene amplification, supposedly due to the same mechanism functioning in breast cancer, may be more effi- ciently treated by this therapy than other pulmonary carcinomas.

This work was partly supported by a Grant-in-Aid for Scientific Research (C) 12670157 from the Japanese Ministry of Education, Science, and Culture.

\section{REFERENCES}

1. Hynes NE, Stern DF. The biology of erbB-2/neu/HER-2 and its role in cancer. Biochim Biophys Acta 1994;1198:165-84.

2. Di Fiore PP, Pierce JH, Kraus MH, Segatto O, King CR, Aaronson SA. erbB-2 is a potent oncogene when overexpressed in NIH/3T3 cells. Science 1987;237:178-82.

3. Slamon DJ, Clark GM, Wong SG, Levin WJ, Ullrich A, McGuire WL. Human breast cancer: correlation of relapse and survival with amplification of the HER-2/ neu oncogene. Science 1987;235:177-82.

4. Slamon DJ, Godolphin W, Jones LA, Holt JA, Wong SG, Keith $\mathrm{DE}$, et al. Studies of the Her-2/neu proto-oncogene in human breast and ovarian cancer. Science 1989;244:707-12.

5. Meden H, Kuhn W. Overexpression of the oncogene c-erbB-2 (HER2/neu) in ovarian cancer: a new prognostic factor. Eur J Obstet Gynecol Repro Biol 1997;71:173-9.

6. Kern JA, Schwartz DA, Nordberg JE, Weiner DB, Green MI, Torney L. p185 neu expression in human lung adenocarcinomas predicts shortened survival. Cancer Res 1990;50:5184-91.

7. Hetzel DJ, Wilson TO, Keeney GL, Roche PC, Cha SS, Podratz KC. HER-2/neu expression: a major prognostic factor in endometrial cancer. Gynecol Oncol 1992;47:179-85.

8. Shi D, He G, Cao S, Pan W, Zhang H-Z, Yu D, et al. Overexpression of the c-erbB-2/neu-encoded p185 protein in primary lung cancer. Mol Carcinog 1992;5:213-8.

9. McCann, Dervan PA, Johnston PA, Gullick WJ, Carney DN. c-erbB-2 oncoprotein expression in primary human tumors. Cancer 1990;65:88-92.

10. Shiraishi M, Noguchi M, Shimosato Y, Sekiya T. Amplification of protooncogene in surgical specimens of human lung carcinomas. Cancer Res 1989;49:6474-9.

11. Cline MJ, Battifora H. Abnormalities of protooncogene in non-small cell lung cancer. Correlations with tumor type and clinical characteristics. Cancer 1987;60:2669-74.

12. Schneider PM, Hung M-C, Chiocca SM, Manning J, Zhao X, Fang K, et al. Differential expression of the c-erbB-2 gene in human small cell and non-small cell lung cancer. Cancer Res 1989;49:4968-71.

13. Slebos RJC, Evers SG, Wagenaar SS, Rodenhuis S. Cellular protooncogenes are infrequently amplified in untreated non-small cell lung cancer. Br J Cancer 1989;59:76-80.

14. Ishikawa T, Kobayashi M, Mai M, Suzuki T, Ooi A. Amplification of the c-erbB-2 (HER-2/neu) gene in gastric cancer cells. Detection by fluorescence in situ hybridization. Am J Pathol 1997;151:761-8.

15. Ooi A, Kobayashi M, Mai M, Nakanishi I. Amplification of c-erbB-2 in gastric cancer: detection in formalin-fixed, paraffin-embedded tissue by fluorescence in situ hybridization. Lab Invest 1998;78:345-51.

16. Pegram MD, Lipton A, Hayes DF, Weber BL, Baselga JM, Tripathy D, et al. Phase II study of receptor-enhanced chemosensitivity using recombinant humanized antip185HER2/neu monoclonal antibody plus cisplatin in patients with HER2/neu-overexpressing metastatic breast cancer refractory to chemotherapy treatment. J Clin Oncol 1998;16:2659-71.

17. Ross JS, Fletcher JA. HER-2/neu (c-erb-B2) gene and protein in breast cancer. Am J Clin Pathol 1999;112(Suppl. 1):S53-67. 
18. Jimenez RE, Wallis T, Tabasczka P, Visscher DW. Determination of Her-2/Neu status in breast carcinoma: comparative analysis of immunohistochemistry and fluorescent in situ hybridization. Mod Pathol 2000;13:37-45.

19. De Potter CR, Beghin C, Makar AP, Vandekerckhove D, Roels HJ. The neu-oncogene protein as a predictive factor for haematogenous metastases in breast cancer patients. Int J Cancer 1990;45:55-8.

20. Persons DL, Bui MM, Lowery MC, Mark HFL, Yung J-F, Birkmeier JM, et al. Fluorescence in situ hybridization (FISH) for detection of HER-2/ neu amplification in breast cancer: a multicenter portability study. Annu Clin Lab Science 2000; 30:41-8.
21. Coene ED, Schelfhout V, De Potter CR. Amplification units and translocation at chromosome $17 \mathrm{q}$ and c-erbB-2 overexpression in the pathogenesis of the breast cancer. Virchows Arch 1997;430:365-72.

22. Pauletti G, Godolphin W, Press MF, Slamon D. Detection and quantitation of HER-2/neu gene amplification in human breast cancer archival material using fluorescence in situ hybridization. Oncogene 1996;13:63-72.

23. Dillman RO. Unconjugated monoclonal antibodies for the treatment of hematologic and solid malignancies. American Society of Clinical Oncology '99 Education Book, 461-8, 1999. 